\title{
Influenza C Virus
}

National Cancer Institute

\section{Source}

National Cancer Institute. Influenza C Virus. NCI Thesaurus. Code C97157.

A negative sense single-stranded RNA virus of the orthomyxovirus family that can cause

a rare form of influenza. Its genome consists of 7 RNA segments that encode 9 proteins. 